\title{
WATER POLLUTION THREATENING MARINE, COASTAL AND ESTUARINE SYSTEMS: A REVIEW OF ENVIRONMENTAL-ECONOMIC APPROACHES FOR THE ASSESSMENT OF DEVELOPMENT STRATEGIES
}

\author{
MARIA I. BASTOS ${ }^{1,2}$, PETER C. ROEBELING ${ }^{2,3}$, FÁTIMA LOPES ALVES $^{2}$ \& SEBASTIAN VILLASANTE ${ }^{1,4}$ \\ ${ }^{1}$ Campus Do*Mar, University of Vigo Campus, Spain \\ ${ }^{2}$ CESAM and Departamento de Ambiente e Ordenamento, University of Aveiro, Portugal \\ ${ }^{3}$ Wageningen Economic Research, Wageningen University and Research (WUR), The Netherlands \\ ${ }^{4}$ Cross-Research in Environmental Technologies (CRETUS), Department of Applied Economics, \\ University of Santiago de Compostela, Spain
}

\begin{abstract}
High-risk industrial pollution is one of the most harmful events threatening natural ecosystems. Water pollution abatement strategies (WPAS) - ranging from mitigation to adaptation strategies - are key to deal with these threats. While WPAS have to be adequately valued and assessed, environmentaleconomic (EE) reasoning - resorting mainly to three analytic tools, namely cost effectiveness analysis (CEA), cost-benefit analysis (CBA) and efficiency analysis (EA) - is critical for developing regional development strategies. This study reviews the state of knowledge on environmental-economic water pollution abatement studies, using a semi-systematic literature review approach. Results show, first, that economic analysis can support the sustainable planning and management of marine, coastal, estuarine and freshwater socio-ecological systems (MCEF-SES), effectively dealing with environmental pollution and push WPAS forward. Second, the most used EE approach within the context of MCEF-SES is CEA (34\%), followed by CBA (19\%), EA (19\%), cost assessment (18\%) and benefit assessment (10\%). Third, until now EE research focused mostly on: (i) the gathering and examination of data; (ii) determining how to assess anthropogenic-induced ecosystem damages; (iii) assessing pollution damages; and (iv) performing CEA of diffuse-source/non-point source pollution. Fourth, even though some works have already been conducted on CBA and spatially explicit dynamic economic models, produced research still concentrates mostly on continuous/diffuse source pollution and oil spills. Out of these, EE scientific research remains sparse. Fifth, CBA is a useful tool to support EE decisions and to explore alternative WPAS, thus supporting better social assessments. Sixth, EA allows for the simultaneous analysis of multiple variables, dimensions and scenarios and is viewed as the most comprehensive of all EE analysis tools. However, most often its complexity limits its usage. Keywords: coastal socio-ecological systems, water pollution, ecosystem impacts, environmentaleconomic approach, mitigation and adaptation strategies.
\end{abstract}

\section{INTRODUCTION}

Changes in land use, industrialization and urbanization, intensify environmental vulnerability and expose marine, coastal, estuarine and freshwater socio-ecological systems (MCEF-SES) to several types and sources of pressure [1]-[4]. Water pollution (WP) types range from continuous-persistent pollution (CPP) to sudden-accidental pollution (SAP), and sources of WP range from point-source pollution (PSP) to diffuse-source pollution (DSP). CPP refers to the sustained, uninterrupted and lingering release of substances that remain in the environment and bio-accumulate through the food-chain [5]. SAP refers to "releases of pollutants that begin abruptly, are fortuitous, and arise without warning, or unexpectedly" [6, p. 617]. PSP is the pollution produced by a stationary site or fixed facility discharging pollutants into the environment, which can easily be traced-back to its origin [7]. Finally, DSP is the pollution coming from dispersed sources with no single source-point or pollution outlet, whose origin is difficult to trace-back to its source [8]. 
The most significant impacts of pollution on water quality include toxic inorganic compounds (heavy metals; toxic elements), toxic organic compounds (pesticides, paints, pharmaceuticals), infectious organisms, oxygen-demanding wastes (sewage, paper/pulp effluents, food-processing wastes), and eutrophication [9]. These, in turn, impact natural ecosystem functions, services and values with subsequent biological and socioeconomic consequences [1], [10], [11]. To halt this dilapidation of natural capital and attain sustainable development, public policies are needed that aim to reinforce ecosystem conservation, remedy persistent adverse consequences of human action on natural ecosystems, improve the way resources are used and mitigate ecological hazards [12].

Water pollution abatement strategies (WPAS) comprehend mitigation and/or adaptation strategies. Mitigation measures seek to decrease or completely stop the likelihood and severity of pollution [13] and, thus, aim at reducing the disposal of water pollutants into the environment [14]. Adaptation measures seek to minimize the impact of emitted pollution, and focus mainly on cleaning operations or remediation measures [15]-[18].

Sustainable economic development requires the valuation of the negative impacts of pollution as well as the estimation of abatement costs, abatement benefits and net welfare gains. However, most economic studies on the subject do not assess the monetary value of ecosystem services (ES) provided by nature, do not consider environmental values in the decision making processes [19] and do not incorporate sociocultural values and the economic impact of the ES on welfare [20]. Environmental-economics aids in the quantification and valuation of benefits provided by the environment, the evaluation of policy instruments and the estimation of welfare implications from sustainable natural resources management in MCEF-SES - thus establishing a bridge between underpinning bio-physical sciences on the one hand and environmental governance and policy on the other hand [21].

Taking the production and protection standpoint analysis of public policies formulation (which balances environmental protection targets and economic development goals), the objective of this paper is to review the current status of environmental-economic knowledge dealing with water pollution threatening MCEF-SES so that research gaps are identified. After presenting the methodology (Section 2), obtained results are summarized and organized in a Cartesian plane (Section 3). Finally, strengths and weaknesses of each environmentaleconomic approach are discussed (Section 4), and knowledge gaps identified (Section 5).

\section{MATERIAL AND METHODS}

This review study focusses on peer-reviewed scientific papers (published in English, between 2000 and 2016) on the economics of MCEF-SES anthropogenic pollution, the strategies to reduce this anthropogenic pollution and the environmental-economic (EE) tools to address them. To this end, the Web of Science (WoS) database and the WoS main collection were used as search tool and primary database.

\subsection{Search method}

A WoS multistep web search based on specific keywords was undertaken, which was completed by a supporting-tier of multiple snow-ball reviews (based on WoS pop-up results when inspecting WoS citations and on the scrutiny of WoS references from key-selected papers). The anchor point of this exploration is the economic approach applied to high-risk WP events threatening MCEF-SES. Using approximately 50 keywords and expressions (see Table 1), the process resulted in 94 selected papers focusing on MCEF water pollution issues, analyzed from an economic perspective. 
Table 1: Web of Science used search topics.

\begin{tabular}{ll}
\hline Rounds & Used search keywords \\
\hline 1st & ["spill", "industrial risk", "industrial disaster", "port risk", "port disaster", \\
& "port hazard"] AND costs AND benefits AND [marine, maritime, coastal, \\
& estuary, lagoon].
\end{tabular}

\subsection{The analytical framework}

Selected papers were organized in a Cartesian plane (Fig. 1), with the horizontal axis representing the type of pollution source (DSP vs. PSP) and the vertical axis representing the type of water pollution (SAP vs. CPP). This results in four quadrants: Q1 demarcated by the PSP and the CPP axes (labelled Ominous Plume quadrant); Q2 defined by the CPP and the DSP axes (labelled Ominous Tide quadrant); Q3 delineated by the DSP and the SAP axes (labelled Toxic Tide quadrant); and Q4 defined by the SAP and the PSP axes (labelled Toxic Plume quadrant). The center of the Cartesian plane is labelled Common-mire.

\section{RESULTS}

\subsection{Synthesis of results}

The 94 selected papers represent studies developed worldwide, with 51 studies focusing on European, 18 on Australian, 13 on North American, eight on Chinese and four on World systems. Fig. 1 shows that the majority of considered papers $(\mathrm{N}=52(55 \%))$ deal with CPP/DSP events (Ominous Tide; Q2), with most of them focusing on nutrient enrichment (20 out of 52) and pollution produced by agriculture activities (15 out of 52) while only few focusing on other types of pollution events (diversified anthropogenic activities, water scarcity and climate change). The second biggest group of papers $(\mathrm{N}=15(16 \%))$ focuses on SAP/PSP events (Toxic Plume; Q4), with nearly all of these papers studying oil spills while only two focusing on industrial hazards. The third group of papers $(\mathrm{N}=12(13 \%))$ focuses on PSP/CPP events (Ominous Plume; Q1), with studies focusing on a variety of topics, like shipping, water treatment and aquaculture. The fourth group of papers $(\mathrm{N}=13(14 \%))$ is generic or covers multiple types of pollution events and, as such, overlaps all four quadrants and sits in the center of the Cartesian plane. Finally, the smallest group of papers $(\mathrm{N}=2$ $(2 \%)$ ) focusses on SAP/DSP events (Toxic Tide; Q3), mostly originated by flooding and associated pollution. 


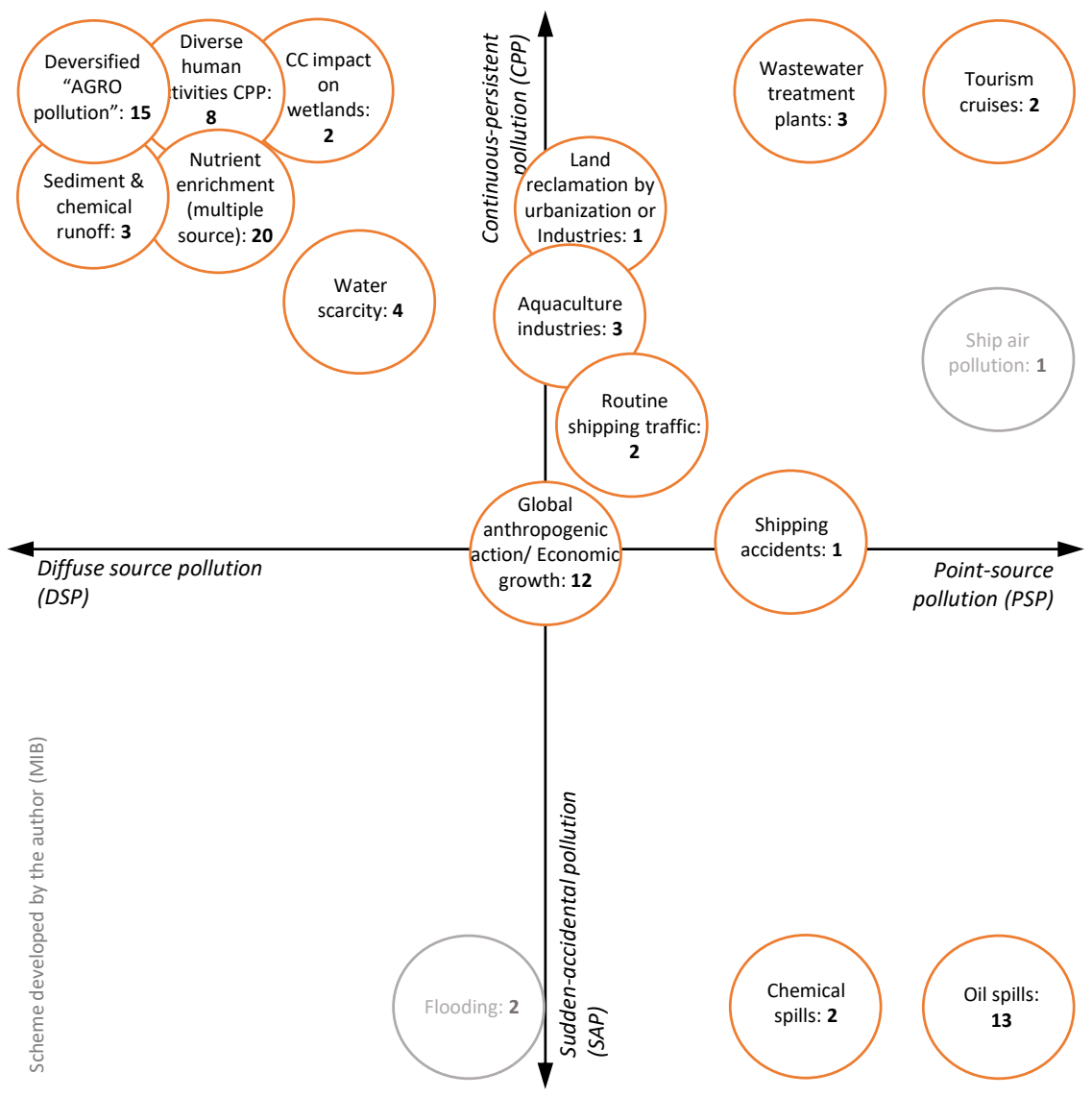

Figure 1: Water pollution types threatening marine, coastal, estuarine and freshwater socio-ecological systems.

\subsection{Description of results per quadrant}

In the Ominous Plume quadrant (PSP/CPP; Fig. 1 and Table 2), one study uses a costeffectiveness (CEA) approach, five studies use a cost-benefit assessment (CBA) approach, five studies use a partial CBA approach (three cost-assessments (CA) and two benefit assessments (BA)) and, finally, one study uses an efficiency assessment (EA) approach. In the Ominous Tide quadrant (CPP/DSP), 28 studies use a CEA approach, 15 studies use an EA approach, five studies use a partial CBA approach (focusing on BA) and four studies use a CBA approach. In the Toxic Tide quadrant (DSP/SAP), the two studies use a CBA approach. In the Toxic Plume quadrant (SAP/PSP), 11 studies use a partial CBA analysis (focusing on CA), two studies use a CBA approach, one study uses a CEA approach and, finally, one study uses an EA approach. Finally, in the Common-mire (center), five studies use a CBA approach, five studies use a partial CBA approach (three focusing on CA and two focusing on BA), two studies uses a CEA approach and one study uses a EA approach. 
Table 2: Assessed measures and used methods in considered studies per quadrant.

\begin{tabular}{|c|c|c|c|c|c|c|c|}
\hline & Study & Measures & Methods & & Study & Measures & Methods \\
\hline \multirow{16}{*}{ 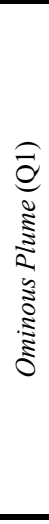 } & \multicolumn{3}{|c|}{ Cost-effectiveness analysis (CEA): 1 study } & \multirow{24}{*}{ 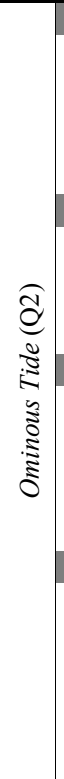 } & \multicolumn{3}{|c|}{ Cost-effectiveness analysis (CEA): 28 st. } \\
\hline & [3] & $\mathrm{M} / \mathrm{A}$ & Valuation methods & & {$[22]$} & \multirow{4}{*}{$\begin{array}{c}\mathrm{M} / \mathrm{A} \\
\ldots \\
\text { Mitigation } \\
\mathrm{M} / \mathrm{A}\end{array}$} & LP \\
\hline & \multicolumn{3}{|c|}{ Cost-benefit analysis (CBA): 5 studies } & & \multirow{3}{*}{$\begin{array}{c}\ldots \\
{[21]} \\
{[28]}\end{array}$} & & \\
\hline & \multirow{4}{*}{$\begin{array}{c}{[23]} \\
\ldots \\
\ldots\end{array}$} & \multirow{4}{*}{$\begin{array}{c}\ldots \\
\text { Mitigation } \\
\ldots \\
\ldots\end{array}$} & \multirow{2}{*}{$\begin{array}{l}\ldots \\
\text { Valuation methods }\end{array}$} & & & & Meta-modelling \\
\hline & & & & & & & LP \\
\hline & & & $\cdots$ & & $\ldots$ & $\ldots$ & $\ldots$ \\
\hline & & & & & & benefit anal & $(\mathrm{CBA}): 4$ studies \\
\hline & & st Assessme & CA): 3 studies & & [29] & Adaptation & Valuation methods \\
\hline & [30] & Adaptation & Valuation methods & & & & $\cdots$ \\
\hline & & ... & & & [31] & $\mathrm{M} / \mathrm{A}$ & Valuation methods \\
\hline & [25] & $\mathrm{M} / \mathrm{A}$ & Valuation methods & & [32] & $\mathrm{M} / \mathrm{A}$ & Valuation methods \\
\hline & & efit Assessm & (BA): 2 studies & & & efit Assessn & (BA): 5 studies \\
\hline & [33] & Mitigation & Valuation methods & & [24] & Adaptation & Valuation methods \\
\hline & [34] & Mitigation & Valuation methods & & ... & $\ldots$ & $\ldots$ \\
\hline & & iciency anal & (EA): 1 study & & $\cdots$ & $\ldots$ & $\cdots$ \\
\hline & [35] & $\mathrm{M} / \mathrm{A}$ & Optimal control & & & $\ldots$ & .. \\
\hline \multirow{3}{*}{2} & \multicolumn{3}{|c|}{ Cost-benefit analysis (CBA): 2 studies } & & [36] & Mitigation & Valuation methods \\
\hline & {$[37]$} & Mitigation & $\mathrm{LP}+\mathrm{VM}$ & & \multicolumn{3}{|c|}{ Efficiency analysis (EA): 15 studies } \\
\hline & [38] & Mitigation & Valuation methods & & \multirow{6}{*}{$\begin{array}{c}{[27]} \\
\ldots \\
{[26]} \\
\ldots \\
{[40]}\end{array}$} & Mitigation & Optimal control \\
\hline \multirow{18}{*}{ 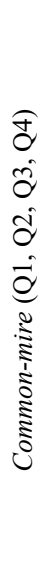 } & Cost- & ectiveness a & ysis (CEA): 1 study & & & $\cdots$ & \\
\hline & [39] & $\mathrm{M} / \mathrm{A}$ & LP & & & $\mathrm{M} / \mathrm{A}$ & Optimal control \\
\hline & [11] & Mitigation & Valuation methods & & & $\ldots$ & \\
\hline & & benefit anal & (CBA): 5 studies & & & Mitigation & Optimal control \\
\hline & [41] & $\mathrm{M} / \mathrm{A}$ & Valuation methods & & & $\cdots$ & 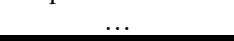 \\
\hline & [42] & $\mathrm{M} / \mathrm{A}$ & Valuation methods & \multirow{13}{*}{ 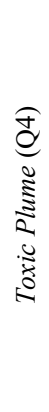 } & \multicolumn{3}{|c|}{ Cost-effectiveness analysis (CEA): 1 study } \\
\hline & & .. & & & [43] & Mitigation & Meta-modelling \\
\hline & [44] & $\mathrm{M} / \mathrm{A}$ & $\mathrm{BBN}$ & & \multicolumn{3}{|c|}{ Cost-benefit analysis (CBA): 2 studies } \\
\hline & ... & ... & ... & & {$[45]$} & $\mathrm{M} / \mathrm{A}$ & Probabilistic $(\mathrm{BBN})$ \\
\hline & \multicolumn{3}{|c|}{ Cost assessment (CA): 3 studies } & & {$[16]$} & Adaptation & Optimal control \\
\hline & [46] & $\mathrm{M} / \mathrm{A}$ & Valuation methods & & \multicolumn{3}{|c|}{ Cost assessment (CA): 11 studies } \\
\hline & [47] & Mitigation & Meta-analysis & & [1] & Adaptation & Valuation methods \\
\hline & [48] & $\mathrm{M} / \mathrm{A}$ & LP & & {$[-3$} & & \\
\hline & \multicolumn{3}{|c|}{ Benefit assessment (BA): 2 studies } & & {$[17]$} & Adaptation & Probabilistic (BBN) \\
\hline & [49] & Mitigation & Valuation methods & & & & 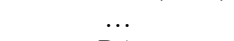 \\
\hline & [50] & $\mathrm{M} / \mathrm{A}$ & LP & & [18] & Adaptation & RA \\
\hline & \multicolumn{3}{|c|}{ Efficiency analysis (EA): 1 study } & & \multicolumn{3}{|c|}{ Efficiency analysis (EA): 1 study } \\
\hline & [51] & $\mathrm{M} / \mathrm{A}$ & Optimal control & & [52] & Mitigation & Optimal control \\
\hline
\end{tabular}

Notes: $\mathrm{M} / \mathrm{A}=$ Mitigation/adaptation; BBN = Bayesian Believe Network; LP = Linear programming;

$\mathrm{CP}=$ Compromising programming; $\mathrm{RA}=$ Regression analysis; $\mathrm{VM}=$ Valuation methods.

CEA studies (32 out of 94 studies) aim to assess which pollution abatement measures achieve pollution reduction targets and/or environmental improvements at least cost [3], [21], [22]. CBA studies (18 out of 94 studies) aim to identify the abatement measure scenario offering the largest net welfare (i.e. difference between costs and benefits [23]). BA studies (nine out of 94 studies) aim to assess the willingness to pay for pollution adaptation measures or determine the benefits from pollution mitigation options [24]. CA studies (17 out of 94 studies) aim to assess the costs of water pollution or the costs of pollution abatement measures [1], [25]. Studies using the EA approach (18 out of 94 studies) aim to identify the portfolio of abatement measures that provide the largest total net welfare [26], [27].

Studied abatement measures in the Ominous Plume quadrant (PSP/CPP) include water pollution mitigation measures (such as improved port safety, shipping traffic and ship characteristics, in-site tertiary treatment of wastewater, and biomitigation) and adaptation measures (such as utilization of sulphur scrubbers and marine gas oil, treatment of emissions, 
waste collection, transportation and disposal). Studied abatement measures in the Ominous Tide quadrant (CPP/DSP) focus mainly on best management practices (such as land retirement, (re)construction of wetlands and riparian buffers) and adaptation measures (such as using coastal waters and wetlands to filter nutrients and care for endangered species). In the Toxic Tide quadrant (DSP/SAP), no studies focusing on water pollution were found. However, given that flooding cause noxious impacts on the quality of MCEF-SES, and flooding mitigation articles can provide valuable insights on EE analysis applied to MCESES, 2 studies focusing on flooding issues were included in the present analysis; both studies assess flood mitigation options by local authorities. Studied abatement measures in the Toxic Plume quadrant (SAP/PSP) include mitigation measures (such as technical improvement of oil tankers and accident prevention measures) and adaptation measures (such as clean-up, oil combating equipment and restoration of ecosystems).

\section{DISCUSSION}

4.1 Water pollution events and impacts on marine coastal, estuarine and freshwater socioecological systems

Research on EE approaches to MCEF-SES pollution shows that continuous diffuse source (Ominous Tide quadrant) and sudden point source (Toxic Plume quadrant) water pollution constitute the most investigated types of events. Investigated continuous point source water pollution (Ominous Plume quadrant) remains miscellaneous and there are no studies focusing explicitly on sudden diffuse source WP; both studies included in this analysis assess flood mitigation options by local authorities (Toxic Tide quadrant; Fig. 1 and Table 2).

In the Ominous Plume quadrant only few EE studies investigate each of the diverse WP events (e.g. shipping traffic, wastewater treatment plants, aquaculture pollution or land reclamation by industry). In the Ominous Tide quadrant most of the EE studies investigate eutrophication induced by sediment and nutrient enrichment of water systems, produced by multiple sources and, specifically, agriculture-related activities; other EE studies in this quadrant focus on a variety of anthropogenic pressures (such as land use change and urbanization), water scarcity, contaminated runoffs and climate change induced impacts. In the Toxic Plume quadrant, the frequency of oil tanker accidents over the last decades and the resulting EE impacts attracted great public and scientific attention, giving rise to an international research effort directed at assessing leakage damages and devising riskminimizing measures [43]. Thus, in this quadrant, EE studies include mostly oil spill accidents, followed by very few chemical industry and processing industry hazards.

\subsection{MCEF-SES pollution abatement strategies}

Apparent in all examined EE papers is the notion that water quality improvement strategies are flexible portfolios of abatement measures, whose composition is defined according to the relative policy priority given by local authorities to environmental protection and economic development. Over the four quadrants, the most investigated abatement strategies are the mixed mitigation and adaptation measures (predominant in the central all-source/all-type Common-mire pollution group, in the Ominous Tide quadrant and the Ominous Plume quadrant; $73 \%, 52 \%$ and $50 \%$ of the considered papers), followed by mitigation measures $(18 \%, 26 \%$ and $43 \%$ of papers). Adaptation strategies are extensively investigated in the Ominous Tide quadrant, the Toxic Plume quadrant and the Common-mire pollution group $(22 \%, 13 \%$ and $9 \%$ of papers). The majority of the Toxic Plume quadrant studies $(60 \%)$ do 
not focus on any specific abatement strategy and opt for remaining generic (the same holds for $7 \%$ of the papers in the Ominous Plume quadrant). Studies in the Toxic Tide quadrant investigate mitigation strategies (Fig. 2(a)).

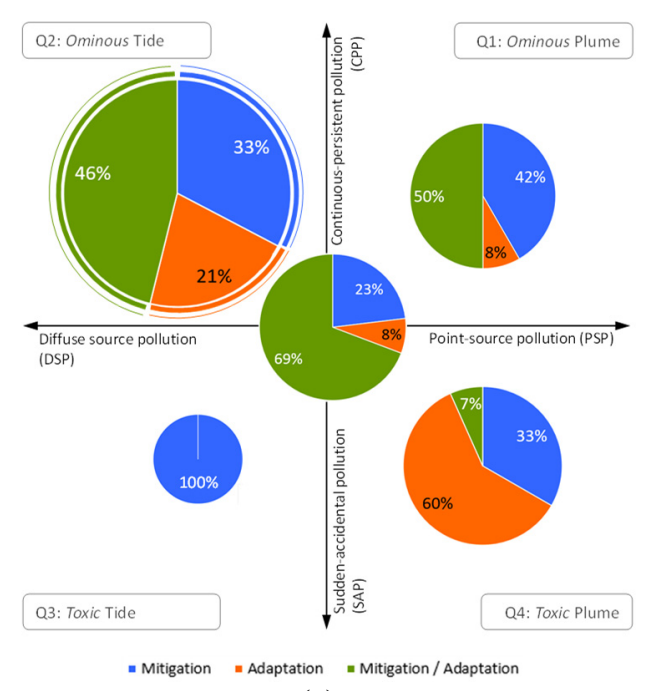

(a)

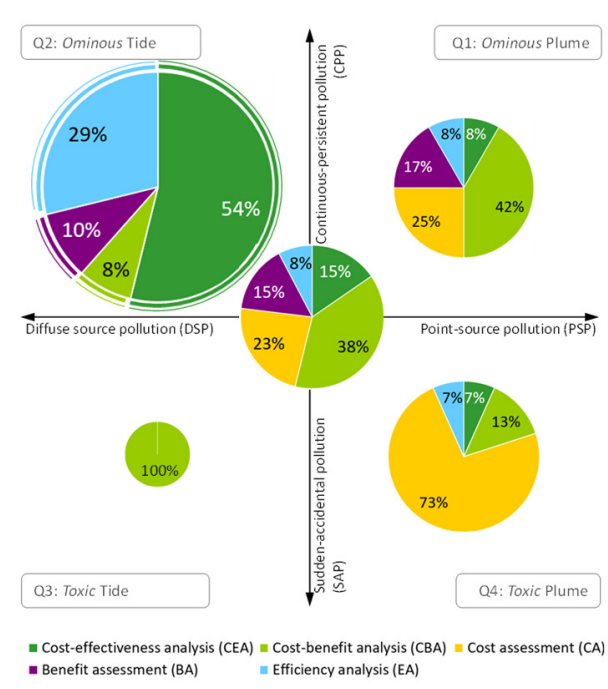

(b)

Figure 2: (a) Identified pollution abatement measures; and (b) EE approaches.

4.3 Environmental-economic approaches to assess production and protection strategies

Environmental-economic (EE) approaches draw mainly on cost-effectiveness analysis (CEA), cost-benefit analysis (CBA) and efficiency analysis (EA). Examined scientific papers cover all EE approaches: cost effectiveness analysis (CEA), full cost-benefit analysis (CBA), partial CBAs (CA or BA) and efficiency analysis (EA) (Fig. 2(b)). Ominous Plume quadrant studies resort to all the EE approaches in a quite balanced way: the full CBA (5 $(36 \%))$, the partial CBAs (CA $(3(21 \%))$ and BA $(2(14 \%)))$, the CEA $(2(14 \%))$ and the EA (2 (14\%)). In the Ominous Tide quadrant, the CEA is the most used approach (27 (54\%)), followed by the EA $(14(28 \%))$, the BA $(5(10 \%))$ and the full CBA $(4(8 \%))$. Toxic Plume studies focus on CA $(11(74 \%))$, followed by the full CBA $(2(13 \%))$, the CEA $(1(7 \%))$ and the EA (1 (7\%)). Both Toxic Tide studies opt for CBA analysis.

EE approaches constitute an important support to the process of policy-formulation, decision-making and the assessment of their premises. Robust EE multi-criteria decision tools, like CBA or EA, can help devising the optimal mix of strategies that most adequately balance environmental protection and economic development objectives, especially if all relevant information is put together in a spatially explicit analysis [45]. Just like traditional economic efficiency requires the whole value of resources to be established and incorporated into private and public decision-making processes, EE efficiency requires a comprehensive evaluation of both environmental costs and benefits [39]. Pollution accidents are rather varied, but it is crucial to control case-specificities and implement appropriate abatement strategies [18]. Thus, ecosystem values and pollution damage costs ought to be integrated 
into EE analysis [53]. Besides the determinants of pollution accidents and their consequences, pollution damage costs are strongly dependent on issues like politics, compensation policies and media coverage of pollution accidents which influence public awareness [1], [13], [18]. Moreover, in the Ominous Tide quadrant, some papers indicate that WP mitigation may come at a private benefit when nutrient emission reductions are low (due to cost savings that outweigh production losses); yet private WP mitigation costs increase exponentially when nutrient emission reductions become larger (due to production losses, see e.g. [21], [28]). Other authors indicate that WP adaptation always comes at a private cost (see e.g. [26]). Regardless of the type of environmental impacts and the lack of consensus among EE experts and stakeholders on how to value and account for both environmental benefits and environmental damages, EE assessment tools prove especially appropriate to estimate these and other environmental impacts (and ecosystem benefits) [1], [30].

\section{CONCLUSIONS}

Negative environmental impacts and ecosystem service value losses resulting from water pollution (WP) events can be large and vary directly with the type of pollutant, the geographic location of pollution occurrence, the geological features and biological characteristics of impacted area, climatological circumstances and the way contaminants spread through the water system. However, as large parts of natural capital services and values remain "outside the market", pollution losses remain widely underestimated.

The objective of this review study is to assess the current knowledge on the environmental-economics (EE) applied to maritime, coastal, estuarine and freshwater socioecological systems (MCEF-SES), focusing on WP pressures. EE studies were mapped in a four quadrant Cartesian plane, having on one axis the type of WP events (sudden to continuous pollution) and on the other axis the type of pollution sources (point to diffuse sources). Five groups of EE studies were mapped: the Ominous Plume quadrant (Q1), the Ominous Tide quadrant (Q2), the Toxic Tide quadrant (Q3), the Toxic Plume quadrant (Q4) and, finally, the Common-mire quadrant (dwelling on all four quadrants).

Results show that, hitherto EE water pollution research focused mostly on (1) the gathering of data and the building of knowledge on how to assess damages induced by human action on ecosystems; (2) the assessment of damages produced by pollution; and (3) the costeffectiveness analysis of diffuse-source/non-point source pollution. Also, WP events associated with sediment and nutrient enrichment from point source pollution (e.g., industrial and residential) to diffuse-source pollution (e.g., agricultural) remain in the spotlight. Overall, the pollution sources considered most troublesome are oil spills, diffuse-source pollution and routine shipping operations, while wastewater, aquaculture, routine cruise tourism, chemical industries and land reclamation also constitute important sources of WP.

The most investigated type of MCEF-SES pollution events, taking an EE perspective, are CPP/DSP events (Ominous Tide quadrant) and oil spills (Toxic Plume quadrant). Further EE research focusing on the Toxic Plume and Ominous Plume quadrants is needed. Besides oil spills, Toxic Plume pollution events have been sparsely investigated until now, namely industrial spills. In the Ominous Plume quadrant, studies tend to focus on wastewater and aquaculture pollution, leaving without attention pollution produced by big industrial compounds. In the Ominous Tide quadrant, most studies investigate eutrophication induced by sediment and nutrient enrichment of water systems produced by multiple sources (mainly agriculture) and a variety of anthropogenic pressures (e.g. land use change, urbanization, water scarcity and contaminated runoffs).

The most used EE approaches to investigate MCEF-SES WP issues are the costeffectiveness analysis (CEA) approach (34\%), followed by the cost-benefit analysis (CBA) 
approach (19\%) and the efficiency analysis (EA) approach (19\%). Partial-CBAs are also used, such as cost-assessment (18\%) and benefit assessment (10\%) studies. Most used methods within the context of WP investigation are valuation methods $(35 \%)$, linear programming (26\%) and optimal control (17\%). Probabilistic Bayesian-belief-network, nonlinear programming, meta-modelling, regression analysis, meta-analysis and compromise programming methods remain marginal within the context of EE research. Staticdeterministic techniques congregate preferences $(50 \%)$, followed by dynamic-deterministic ones $(30 \%)$.

In an analysis by quadrant, CEA is the most used EE tool to investigate CPP/DSP pollution events (Ominous Tide quadrant) and helps assuring economic efficiency of environmental management measures, by including in the analysis both the costs of pollution abatement and corresponding environmental impacts. The most used EE tool to investigate $\mathrm{PSP} / \mathrm{CPP}$ pollution events (Ominous Plume quadrant) is CBA that aims to assess the welfare benefits from abatement strategy scenarios. Hence, CBA is useful in assessing trade-offs between the economic benefits from environmental protection and economic development. The second most used EE tool to investigate CPP/DSP pollution events (Ominous Tide quadrant) is EA that allows for the simultaneous analysis of multiple variables, dimensions and scenarios and is viewed as the most comprehensive and flexible of all EE analysis tools. However, its complexity may limit its usage.

When environmental impacts of human activities are not properly valued, incorporated into cost structures or counted-in the final market prices of products and services, market distortions occur and environment policies are ineffective. Research shows that profit seekers tend to opt for defensive and cost-effective pollution remedying measures, instead of large (long-term) investments in costly clean and pollution-preventing technologies. Thus, to avoid further costs from externalities, current and future impacts of environmental pollution produced by industries, infrastructures and urban settlements ought to be evaluated, together with a comprehensive valuation of ecosystems and services (also including non-market values) so that both the value of biodiversity and ecosystem services and the costs of pollution are taken into account in decision-making.

In conclusion, environmental-economic analysis can aid and support the implementation of ecosystem-based management of MCEF-SES and is viewed as an effective approach to deal with environmental degradation and help push forward relevant pollution abatement strategies. However, it is evident from the literature that context, spatially and temporally explicit assessments, at scales meaningful for policy formulation, require the development of spatially explicit models that consider bio-physical and socio-economic heterogeneity.

Some caveats remain and some important research knowledge gaps have been identified. First, most of natural capital and ecosystem service values remain "outside the market" and its consumption remains unvalued, allowing for environmental depletion and negative externalities to persist. Thus, the value of biodiversity and ecosystem services ought to be comprehensively valued, assessed and taken into account; moreover, pollution costs ought to be fully internalized. Specifically, there is a particular need to: (i) to capture the full range of ecosystem services and values; (ii) to develop bio-physical measures and indicators of biodiversity and ecosystems, suitably related to socio-economic attributes of ecosystem valuation; (iii) to develop economic assessments that are context, spatially and temporally explicit at scales meaningful for policy formulation; (iv) to integrate analyses of risks, uncertainties, irreversibility and resilience in environmental-economic assessments and valuation studies; and (v) to develop robust complex systems modelling approaches that integrate linkages between biodiversity, ecosystem services and human well-being. 


\section{ACKNOWLEDGEMENTS}

This study is part of the thesis of a PhD Programme on Marine Science, Technology and Management (Do*Mar). Thanks are due, for the financial support, to CESAM (UIDB/50017/2020 and UIDP/50017/2020), to FCT/MCTES through national funds, and to the co-funding by European funds when applicable. Thanks are also due to the UNaLab project, financed by the EU Horizon 2020 research and innovation program under grant agreement No. 730052: Topic: SCC-2-2016-2017: Smart Cities and Communities Nature based solutions. Finally, thanks are due to the financial support of the Xunta de Galicia for financial aid through project GPC 2013-045, the ICES Science Fund to the project "Social transformations of marine social-ecological systems" and the EC "Ocean governance for sustainability challenges, options and the role of science" (COST Action CA15217).

\section{REFERENCES}

[1] Depellegrin. D. \& N. Blazauskas, N., Integrating ecosystem service values into oil spill impact assessment. J. Coast. Res., 29(4), pp. 836-846, 2012.

[2] Roebeling, P.C., Hendrix, E.M.T. \& Van Grieken, M.E., Exploring industry specific social welfare maximizing rates of water pollution abatement in linked terrestrial and marine ecosystems. J. Coast. Res., 56, pp. 1681-1685, 2009.

[3] Xue, M. \& Luo, Y., Dynamic variations in ecosystem service value and sustainability of urban system: A case study for Tianjin city, China. Cities, 46, pp. 85-93, 2015.

[4] Wen, Z. \& Chen, J., A cost-benefit analysis for the economic growth in China. Ecol. Econ., 65(2), pp. 356-366, 2008.

[5] GreenFacts, Persistent organic pollutants, 2018. https://www.greenfacts.org/glossary/ pqrs/persistent-organic-pollutants-POPs.htm. Accessed on: 19 Jan. 2018.

[6] Ballard, N. \& Manus, P.M., Clearing muddy waters: Anatomy of the comprehensive general liability pollution exclusion. Cornell Law Rev., 75(3), pp. 610-643, 1990.

[7] Aquarium of the Pacific, Pollution and Health, 2016. https://www.aquariumofpacific.org/mcri/pollution_and_health.

[8] EPA, Nonpoint source (NPS) pollution, 2016. https://www.epa.gov/nps/basicinformation-about-nonpoint-source-nps-pollution.

[9] Walmsley, J.J., Framework for measuring sustainable development in catchment systems. Environ. Manage., 29(2), pp. 195-206, 2002.

[10] Stam, G.J., Bottelberghs, P.H. \& Post, J.G., Environmental risk: Towards an integrated assessment of industrial activities. J. Hazard. Mater., 61(1-3), pp. 371-374, 1998.

[11] Walker, W.E., POLSSS: Overview and cost-effectiveness analysis. Saf. Sci., 35, 2000.

[12] Islam, M.S. \& Tanaka, M., Impacts of pollution on coastal and marine ecosystems including coastal and marine fisheries and approach for management: A review and synthesis. Mar. Pollut. Bull., 48(7-8), pp. 624-649, 2004.

[13] Psarros, G., Skjong, R. \& Vanem, E., Risk acceptance criterion for tanker oil spill risk reduction measures. Mar. Pollut. Bull., 62(1), pp. 116-127, 2011.

[14] Gren, I., Adaptation and mitigation strategies for controlling stochastic water pollution: An application to the Baltic Sea. 6, 2008.

[15] Kontovas, C.A., Psaraftis, H.N. \& Ventikos, N.P., An empirical analysis of IOPCF oil spill cost data. Mar. Pollut. Bull., 60(9), pp. 1455-1466, 2010.

[16] Monte, L., Brittain, J.E., Gallego, E., Håkanson, L., Hofman, D. \& Jiménez-Martin, A., MOIRA-PLUS: A decision support system for the management of complex fresh water ecosystems contaminated by radionuclides and heavy metals. Comput. Geosci., 35(5), pp. 880-896, 2009. 
[17] Montewka, J., Weckström, M. \& Kujala, P., A probabilistic model estimating oil spill clean-up costs: A case study for the Gulf of Finland. Mar. Pollut. Bull., 76(1-2), pp. 61-71, 2013.

[18] Ventikos, N.P. \& Sotiropoulos, F.S., Disutility analysis of oil spills: Graphs and trends. Mar. Pollut. Bull., 81(1), pp. 116-123, 2014.

[19] Villasante, M., Sumaila, S. \& Antelo, R., Why cooperation is better: The gains to cooperative management of the Argentine shortfin squid fishery in South America. Environment and Development Economics: Essays in Honour of Sir Partha Dasgupta, Oxford University Press, pp. 271-294, 2014.

[20] Mach, M.E., Martone, R.g. \& Chan, K.M.A., Human impacts and ES: Insufficient research for trade-off evaluation. Ecosyst. Serv., 16, pp. 112-120, 2015.

[21] Roebeling, P., Rocha, J., Nunes, J.P., Fidélis, T., Alves, H. \& Fonseca, S., Using the soil and water assessment tool to estimate dissolved inorganic nitrogen water pollution abatement cost functions in central portugal. J. Environ. Qual., 43(1), pp. 168-176, 2014.

[22] Ahlvik, L., Ekholm, P., Hyytiäinen, K. \& Pitkänen, H., An economic-ecological model to evaluate impacts of nutrient abatement in the Baltic Sea. Environ. Model. Softw., 55, pp. 164-175, 2014.

[23] Djukic, M., Jovanoski, I., Munitlak, O. \& Lazic, M., Cost-benefit analysis of an infrastructure project and a cost-reflective tariff: A case study for investment in wastewater treatment plant in Serbia. 59, pp. 1419-1425, 2016.

[24] Faccioli, M., Riera Font, A. \& Torres Figuerola, C.M., Valuing the recreational benefits of wetland adaptation to climate change: A trade-off between species' abundance and diversity. Environ. Manage., 55(3), pp. 550-563, 2015.

[25] Ng, A.K.Y. \& Song, S., The environmental impacts of pollutants generated by routine shipping operations on ports. Ocean Coast. Manag., 53(5-6), pp. 301-311, 2010.

[26] Roebeling, P., Cunha, M.C., Arroja, L. \& Van Grieken, M.E., Abatement vs. treatment for efficient diffuse source water pollution management in terrestrial-marine systems. Water Sci. Technol., 72(5), pp. 730-737, 2015.

[27] Doole, G.J. \& Romera, A.J., Implications of a nitrogen leaching efficiency metric for pasture-based dairy farms. Agric. Water Manag., 142, pp. 10-18, 2014.

[28] Roebeling, P.C., Van Grieken, M.E., Webster, A.J. \& Biggs, J., Cost-effective water quality improvement in linked terrestrial and marine ecosystems: a spatial environmental-economic modelling approach. Mar. Freshw. Res., pp. 1150-1158, 2009.

[29] Birol, E., Koundouri, P. \& Kountouris, Y., Assessing the economic viability of alternative water resources in water-scarce regions: Combining economic valuation, cost-benefit analysis and discounting. 69, pp. 839-847, 2010.

[30] Caric, H., Challenges and prospects of valuation: Cruise ship pollution case. 111, 2016.

[31] Lei, L., Jian, L., Yutao, W., Nvjie, W. \& Renqing, W., Cost-benefit analysis and payments for watershed-scale wetland rehabilitation: A case study in Shandong Province, China. 5(3), pp. 787-796, 2011.

[32] Martínez-Paz, J.M., Perni, A. \& Martínez-Carrasco, F., Assessment of the programme of measures for coastal lagoon environmental restoration using cost-benefit analysis. Eur. Plan. Stud., 21(2), pp. 131-148, 2013.

[33] Martínez-Espiñeira, R., Chopin, T., Robinson, S., Noce, A., Knowler, D. \& Yip, W., Estimating the biomitigation benefits of integrated multi-trophic aquaculture: A contingent behavior analysis. Aquaculture, 437, pp. 182-194, 2015. 
[34] Martinez-Espiñeira, R., Chopin, T., Robinson, S., Noce, A., Knowler, D. \& Yip, W., A contingent valuation of the biomitigation benefits of integrated multi-trophic aquaculture in Canada. Aquac. Econ. Manag., 20(1), pp. 1-23, 2016.

[35] Doyle, M.W., Patterson, L.A., Chen, Y., Schnier, K.E. \& Yates, A.J., Optimizing the scale of markets for water quality trading. AGU Publ. - Water Resour. Res., pp. 72317244, 2014.

[36] Zander, K.K., Garnett, S.T. \& Straton, A., Trade-offs between development, culture and conservation: Willingness to pay for tropical river management among urban Australians. J. Environ. Manage., 91(12), pp. 2519-2528, 2010.

[37] Broekx, S., Smets, S., Liekens, I., Bulckaen, D. \& de Nocker, L., Designing a longterm flood risk management plan for the Scheldt estuary using a risk-based approach. Nat. Hazards, 57(2), pp. 245-266, 2011.

[38] de Nocker, L. et al., Cost-benefit analysis to select the optimal flood protection strategy along the Scheldt. WIT Trans. Ecol. Environ., vol. 91, WIT Press: Southampton and Boston, pp. 271-277, 2006.

[39] Oinonen, S. et al., Cost-effective marine protection: A pragmatic approach. PLoS One, 11(1), pp. 1-19, 2016.

[40] Roebeling, P., Alves, H., Rocha, J., Brito, A., Almeida, P. \& Mamede, J., Gains from trans-boundary water quality management in linked catchment and coastal socioecological systems: A case study for the Minho region. Water Resour. Econ., 8, pp. 32-42, 2014.

[41] Bertram, C. \& Rehdanz, K., On the environmental effectiveness of the EU Marine Strategy Framework Directive. Mar. Policy, 38, pp. 25-40, 2013.

[42] Bertram, C., Dworak, T., Görlitz, S., Interwies, E. \& Rehdanz, K., Cost-benefit analysis in the context of the EU Marine Strategy Framework Directive: The case of Germany. Mar. Policy, 43, pp. 307-312, 2014.

[43] Vanem, E., Endresen, Ø. \& Skjong, R., Cost-effectiveness criteria for marine oil spill preventive measures. Reliab. Eng. Syst. Saf., 93(9), pp. 1354-1368, 2008.

[44] Scharin, H. et al., Processes for the sustainable stewardship of marine environments. Ecol. Econ., 128, pp. 55-67, 2016.

[45] Helle, I., Ahtiainen, H., Luoma, E., Hanninen, M. \& Kuikka, S., A probabilistic approach for a cost-benefit analysis of oil spill management under uncertainty: A BN model for the Gulf of Finland. J Env. Manag., 158, pp. 122-132, 2015.

[46] Levrel, H. et al., The maintenance costs of marine natural capital: A case study from the initial assessment of the Marine Strategy Framework Directive in France. Mar. Policy, 49, pp. 37-47, 2014.

[47] Sobota, D.J., Compton, J.E., Mccrackin, M.L. \& Singh, S., Cost of reactive nitrogen release from human activities to the environment in the United States Cost of reactive nitrogen release from human activities to the environment in the US. 2015.

[48] Zhang, K., Li, Y.P., Huang, G.H., You, L. \& Jin, S.W., Modeling for regional ecosystem sustainable development under uncertainty: A case study of Dongying, China. 533, pp. 462-475, 2015.

[49] Blau, J. \& Green, L., Assessing the impact of a new approach to ocean management: Evidence to date from five ocean plans. Mar. Policy, 56, pp. 1-8, 2015.

[50] Wang, W., Guo, H., Chuai, X. \& Dai, C., The impact of land use change on the temporospatial variations of ecosystems services value in China and an optimized land use solution. Environ. Sci. Policy, 44(5), pp. 62-72, 2014. 
[51] You, L., Li, Y.P., Huang, G.H. \& Zhang, J.L., Modeling regional ecosystem development under uncertainty: A case study for New Binhai District of Tianjin. 288, pp. 127-142, 2014.

[52] Di Jin, H., Kite-Powell, L. \& Broadus, J., Dynamic economic analysis of marine pollution prevention technologies: An application to double hulls and electronic charts. Environ. Resour. Econ., 4, pp. 555-580, 1994.

[53] Loureiro, M.L., Loomis, J.B. \& Vázquez, M.X., Economic valuation of environmental damages due to the prestige oil spill in Spain. Environ. Resour. Econ., 44(4), pp. 537$553,2009$. 